\title{
AS OBSERVAÇÕES DE WITTGENSTEIN SOBRE O TEOREMA DE GÖDEL ${ }^{1}$
}

\author{
Camila Jourdan (UERJ) $)^{2}$ \\ camilajourdan@hotmail.com
}

\begin{abstract}
Não há como um matemático não ficar horrorizado com meus comentários matemáticos, já que foi sempre treinado para evitar a indulgência com pensamentos e dúvidas do tipo que desenvolvo. (Wittgenstein, PG, II, V, 25)
\end{abstract}

Resumo: $\mathrm{O}$ artigo analisa os muito malvistos comentários de Wittgenstein sobre o teorema de Gödel. Não se pretende defender esses comentários, nem atribuir a Wittgenstein algo que ele não disse. De fato, não nos seria possível desconsiderar o que é textual visando fornecer uma interpretação mais palatável das posições de um autor. Nosso objetivo consiste meramente em clarificar as posições realmente mantidas por Wittgenstein sobre o tema, atribuindo, tanto quanto possivel, alguma razoabilidade às mesmas no que diz respeito à economia geral das suas observações sobre a matemática.

Palavras-chave: Wittgenstein; Matemática; Gödel; Hilbert; Ômegainconsistência.

\section{INTRODUÇÃO}

É uma opinião comumente aceita que Wittgenstein não compreendeu o teorema de Gödel. Além de Kreisel, Bernays e Dummett, foi o próprio Gödel quem, como se sabe, afirmou categoricamente, em uma carta a Menger, que Wittgenstein não entendera seu teorema:

\footnotetext{
${ }^{1}$ Recebido: 08-04-2012/Aprovado: 14-05-2013/Publicado on-line: 17-02-2013.

${ }^{2}$ Camila Jourdan é Professora Adjunta do Departamento de Filosofia da Universidade do Estado do Rio de Janeiro, Rio de Janeiro, RJ, Brasil.
} 
Relativamente ao meu teorema que trata das proposições indecidíveis, é na realidade claro pelas passagens que você cita que Wittgenstein não o compreendeu (ou fingiu não o ter compreendido). Ele interpreta-o como uma espécie de paradoxo lógico, quando de fato é precisamente o oposto, nomeadamente um teorema matemático dentro de uma parte da matemática absolutamente incontroversa (teoria dos números finitos ou combinatórios). A propósito disso, toda a passagem que você cita parece-me disparatada. Veja e.g. o 'medo supersticioso dos matemáticos perante as contradições'. (Gödel apud Wang 1991, 92)

Por outro lado, aqueles que tentam defender a leitura de Wittgenstein atentam principalmente para o fato de que suas críticas aplicam-se não propriamente ao teorema, mas à interpretação filosófica deste - o que ele chama de 'a prosa sobre o cálculo', que envolveria uma confusão acerca das noções de verdade e demonstrabilidade (cf. Floyd 2002). Wittgenstein não estaria criticando o teorema, mas estaria criticando uma leitura metafísica do teorema, que o utilizaria como prova do platonismo matemático, a partir da conclusão, atribuída à prova, segundo a qual a verdade não poderia ser equacionada com a demonstrabilidade. Gödel teria provado que existem verdades matemáticas indemonstráveis ou, mais forte ainda, que a verdade ultrapassa a demonstrabilidade, e são formulações como estas que Wittgenstein não aceita, pois considera expressões de uma confusão filosófica. O que Wittgenstein está criticando é, primariamente, a própria pretensão de se provar matematicamente uma verdade metafísica, como se o teorema tivesse demonstrado uma tese filosófica. Como se sabe, uma posição bastante cara a Wittgenstein é aquela segundo a qual as teses filosóficas não podem ser demonstradas, desde que se restrinjam às questões conceituais, que devem ser submetidas à análise. Se é assim, tal como Wittgenstein afirma em sua obra, a prova de Gödel pode estar expressando um limi- 
te para nossos conceitos, mas não pode estar provando nenhuma tese ontológica: "Pode ser perguntado: que importância tem a prova de Gödel para nosso tipo de trabalho? Pois uma parte da matemática não pode resolver problemas do tipo que nos perturbam" (RFM, VII, 22). A questão central de Wittgenstein é justamente: 'o que podemos ou não compreender do teorema de Gödel?'. E, de fato, essa abordagem não se restringe a sua leitura de Gödel, mas aplica-se a todas as suas polêmicas passagens contra Russell, Cantor, ou Dedekind, em relação aos quais Wittgenstein também pretendeu erguer uma análise gramatical relativa à interpretação filosófica de seus resultados:

Não é minha tarefa atacar a lógica de Russell de dentro, mas de fora. Isso significa dizer: não atacá-la matematicamente - de outro modo eu deveria estar fazendo matemática - mas sua posição, sua função. Minha posição não é falar sobre a prova de Gödel, mas ultrapassá-la. (RFM, VII, 19)

Contudo, de fato, Wittgenstein interpreta a sentença de Gödel, em algumas passagens, como um paradoxo análogo ao paradoxo do mentiroso, e é em relação a esse ponto que se aplica, mais diretamente, a acusação de que ele não teria compreendido o teorema de Gödel. No que se segue, pretendemos conferir alguma razoabilidade às passagens de Wittgenstein sobre Gödel, mostrando a coerência destas com as demais posições mantidas pelo autor. Fazendo isso, apresentamos e explicamos a interpretação que Juliet Floyd e Hilary Putnam propõem, avaliando em que medida tal proposta é plausível. Finalmente, comentamos como as críticas de Wittgenstein a Gödel podem ser ditas aplicarem-se primariamente ao problema de princípio inerente à própria demanda do programa de Hilbert. 


\section{O TEOREMA DE GÖDEL E O DISCURSO MATEMÁTICO}

A crítica mais repetida por Wittgenstein, relativa à prova de Gödel, diz respeito à interpretação da prova como estabelecendo que a sentença $G$, indecidível, seria verdadeira ainda que indemonstrável. Primeiramente, a razão para Wittgenstein recusar que a sentença de Gödel seja entendida como verdadeira, ainda que indemonstrável, parece dizer respeito à sua própria concepção acerca da natureza das proposições matemáticas. É uma tese geral wittgensteiniana que, onde faz sentido falar em verdade, o sentido da proposição deve ser determinado independentemente da sua verdade ou falsidade e, por isso, a proposição pode ser verdadeira ou falsa. Por outro lado, o âmbito da linguagem em que se expressa necessidade estabeleceria os critérios a partir dos quais poderíamos julgar se uma dada sentença é verdadeira ou falsa, e esse âmbito seria normativo. $\mathrm{O}$ âmbito da matemática é então entendido, por Wittgenstein, como completamente normativo, posto que completamente composto por proposições necessárias. Nesse âmbito, a determinação da verdade não seria independente da determinação da semântica e, por isso, se vamos continuar falando em 'verdade' no contexto da aritmética será somente em um sentido no qual não apenas 'ser demonstrável' é o sentido de 'verdade' primário, como também esta própria demonstrabilidade determina o significado das proposições ou fórmulas, não fazendo sequer sentido falar de uma proposição matemática independentemente de sua demonstração. Assim, supor que uma sentença que afirma de si mesma que não é demonstrável, é verdadeira ainda que indemonstrável no sistema, por um critério externo, parece ser também supor que o próprio âmbito da determinação do significado da 
sentença é, de alguma forma, também julgado por critérios externos, tendo em vista algum padrão independente à demonstrabilidade no sistema, que determinaria ao mesmo tempo a verdade e a semântica da proposição (suas condições de verdade), e é essa posição, associada ao realismo matemático por Wittgenstein, que o autor deseja recusar. Dito de outro modo: como a matemática é um âmbito normativo, a demonstrabilidade encontra-se equacionada à verdade. As análises de Wittgenstein do contexto normativo da matemática têm como conclusão que, nesse contexto, não há e nem pode haver um critério externo em virtude do qual pudéssemos dizer que a sentença é verdadeira para além da sua demonstrabilidade. Isso porque a demonstrabilidade seria constitutiva do sentido da sentença. Como, em relação ao âmbito da matemática, Wittgenstein conclui, em princípio, que as possibilidades de uma sentença encontram-se colapsadas às suas possibilidades factuais, dizer que uma sentença é demonstrável ${ }^{3}$ é o único sentido no qual poderíamos dizer que a sentença é verdadeira. Não haveria, independentemente da prova, o sentido da sentença já determinado, e, assim, não teríamos em que nos basear para dizer que a sentença é, apesar de indemonstrável, verdadeira. Como a sentença é necessária (desde que se trata de uma sentença matemática), a verdade da sentença seria dada com seu sentido. Talvez por isso Wittgenstein compare a sentença de Gödel com uma sentença empírica, objetivan-

\footnotetext{
${ }^{3}$ No caso, dizer que uma sentença é demonstrável seria também o mesmo que dizê-la demonstrada. No geral, uma sentença demonstrável não é necessariamente demonstrada. Mas, se esse fosse o caso para as sentenças matemáticas, haveria uma possibilidade em princípio determinada independentemente da demonstração neste âmbito, o que Wittgenstein recusa. Para Wittgenstein, portanto, não haveria sentença matemática demonstrável não demonstrada. Mantemos aqui a terminologia 'demonstrável' apenas para clarificar como fica o diálogo nesses termos com a tradição que aceita essa distinção no âmbito matemático.
} 
do deixar claro que o que se conclui para a sentença de Gödel, no final das contas, é o que se esperaria como natural de uma sentença contingente, que pode ser verdadeira ou não sem deixar de ter sentido. Por outro lado, se entender a sentença for entendê-la como demonstrável, dizer que essa sentença pode ser verdadeira ainda que indemonstrável é necessariamente confundir o âmbito necessário da linguagem com o âmbito contingente e, com isso, tratar o impossível como possível, que é o que ocorre quando proferimos absurdos.

Mas é provavelmente diferente - se eu digo: chove; ou: a proposição 'chove' depreende-se consequentemente adiante! Mas e se as proposições apenas fossem reconhecidas por depreenderem-se delas, e se se seguir daquelas fosse o único critério que nós estabelecemos como válido para a correção de 'chove'? (Wittgenstein 2000, item 121 85r)

Se for assim, uma sentença que se afirma indemonstrável estaria dizendo-se impossível, e não poderia ser verdadeira sem contradição, do que se seguiria em grande medida o próprio caráter paradoxal que Wittgenstein atribui à sentença: "Bem, se você lê esta proposição e (por exemplo) diz: auto-evidente; então se pode atribuir a você uma contradição" (Wittgenstein 2000, item 121 80r).

Vemos assim a importância de mantermos como pano de fundo as considerações gerais de Wittgenstein sobre as provas e as proposições matemáticas para melhor entendermos seus comentários sobre Gödel. Mas, com isso, apesar de Wittgenstein possuir razões independentes para sua abordagem das proposições matemáticas, parece muito que caberia a Wittgenstein justificar sua posição antes do que, com base nela, rejeitar a interpretação que se faz do resultado de Gödel. Mais do que isso, parece que Wittgenstein sustenta uma teoria semântica em grande medida antirrea- 
lista, e, com base nesta, pretende interditar uma interpretação do resultado de Gödel que, justamente, colocaria tal teoria em cheque. Dessa forma, Wittgenstein incorreria em uma clara petição de princípio, e é isso que afirma inclusive alguém bastante simpático com relação ao ponto de vista de Wittgenstein, como Glock (1998, 105-106):

Wittgenstein não pôs em questão a validade da prova, mas somente a interpretação de 'P' como um enunciado que afirma ser ao mesmo tempo indemonstrável e verdadeiro. Um de seus argumentos é que essa interpretação é paradoxal, já que, para que ' $P$ ' seja verdadeiro em $\mathrm{S}$, deve ou ser um axioma de $\mathrm{S}$ ou ter sido demonstrado a partir de tais axiomas. [...] [a linha de argumentação] pressupõe, entretanto, a sua visão de que uma sentença só constitui uma verdade matemática dotada de significado se tiver sido derivada de um sistema de prova específico. Sem razões independentes para essa visão, o ataque de Wittgenstein a Gödel peca por petição de princípio, uma vez que a interpretação de Gödel implica precisamente que há um abismo entre significado e verdade matemáticos, por um lado, e prova e demonstrabilidade matemáticas, por outro.

Como responder então a essa objeção? O caminho passa por notar que, para Wittgenstein, é a interpretação filosófica da sentença de Gödel como sendo verdadeira, porém indemonstrável, que supõe já o realismo do significado, e que, assim, se essa interpretação é usada como uma evidência (ou mesmo uma prova) do realismo, Wittgenstein pode inverter a acusação de petição de princípio para aquele que o acusa. Esse não é, de fato, o ponto mais difícil de defender em meio às demais observações de Wittgenstein, quase sempre obscuras e polêmicas. Tem sido largamente notado que a prova de Gödel não afirma nem poderia afirmar nada sobre a verdade da sentença G. Como salienta, por exemplo, Torkel Franzén, todas as sentenças verdadeiras na prova de Gödel são de fato demonstradas e, dado que a sentença $G$, pelo segundo teorema de incompletude, seria 
mesmo equivalente à consistência do sistema, a impossibilidade de se provar $G$ no sistema equivaleria mesmo à impossibilidade do sistema provar sua própria consistência:

[...] é freqüentemente dito que a prova de Gödel mostra que $G$ é verdadeira, ou 'em algum sentido' verdadeira. Mas a prova não mostra $G$ verdadeira. $O$ que aprendemos da prova é que $G$ é verdadeira se e apenas se $\mathrm{S}$ é consistente. Nessa observação, não existe razão para usar qualquer formulação como 'em algum sentido verdadeira' [...]. A prova de Gödel não mostra que existe qualquer enunciado aritmético que sabemos ser verdadeiro, mas não é provável em $\mathrm{S}$, pois o enunciado 'S é consistente se e apenas se G' é provável em $\mathrm{S}$ [...]. (Franzén 2005, 99)

Charles Sayward também recentemente defendeu os argumentos de Wittgenstein, mantendo que a leitura da sentença de Gödel como uma verdade indemonstrável já suporia a concepção platônica de verdade e que, portanto, o teorema de Gödel não poderia ser legitimamente entendido como provando o platonismo:

$\mathrm{O}$ argumento A [que estabelece a existência de sentenças verdadeiras, mas indemonstráveis em um dado sistema] pressupõe, em geral, que a verdade é o mesmo tipo de coisa em cada área na qual falamos da verdade, e que a verdade matemática, em particular, é uma noção sistema-independente. Esta tese é uma tese filosófica. Se não a aceitamos, não precisamos aceitar o argumento A. (Sayward 2001, 267)

O ponto de Sayward é que a noção clássica de semântica e de verdade (de semântica determinada por condições e verdade) pressuporia que todas as sentenças teriam um valor de verdade determinado, e tal pressuposição é que estaria na base da interpretação da sentença de Gödel como provando que nossos métodos de verificação não alcançam todas as verdades que existem. Uma leitura antirrealista, tal como a mantida por Dummett, por exemplo, ao contrário, entende justamente que a prova de Gödel revelaria que a 
matemática "tem buracos" de valor de verdade (cf. Dummett 1978, 186-191). Wittgenstein, por seu turno, também não aceitaria isso porque sua posição é, antes, que a prova, enquanto prova matemática, não poderia provar qualquer posição filosófica, nem realista, nem antirrealista.

O que Wittgenstein afirma, expressamente (cf. RFM, I, Ap. III, 8), é que se uma proposição que se diz indemonstrável for falsa, não será indemonstrável, mas será demonstrável, e, portanto, verdadeira. Por outro lado, se a tomarmos como verdadeira, mas não demonstrável no sistema, a aparência paradoxal é eliminada. E é, de fato, o que também nos diz Smullyan (2001, 73):

Ao invés de um paradoxo, existe agora uma interessante verdade nomeadamente, que a sentença acima deve ser uma verdade que não é demonstrável no sistema $S$, porque se ela fosse falsa, diferentemente do que dissemos, seria provável no sistema S, contrariando o dado fato de que $S$ é um sistema correto que nunca prova qualquer sentença falsa. Então, a sentença é verdadeira e então também não demonstrável no sistema.

Parece assim que ser verdadeira (no sistema) não pode significar ser demonstrável (no sistema), porque se a sentença que afirma de si mesma que não é demonstrável fosse verdadeira e, com isso, demonstrável no sistema, seria falsa. "Estabelecemos a condição de verdade: se a sentença é provável, deve ser falsa" (Wittgenstein 2000, item 121 79r). O ponto de Wittgenstein então parece ser: ser verdadeiro não pode significar ser demonstrável justamente para se evitar o caráter paradoxal da sentença (ou um limite conceitual expresso por ela). Assim, não pode haver uma relação de interdependência entre a verdade e a demonstrabilidade. Para Wittgenstein, a interpretação da proposição como verdadeira procederia apenas na direção de eliminar a limitação ex- 
pressa pela sentença, que não é então simplesmente aceitar como um resultado limitativo por conta já da suposição de uma posição (prosa) filosófica realista. A interpretação realista da prova expressaria, para Wittgenstein, uma mudança no uso de nossos conceitos, e, portanto, uma questão da ordem da confusão conceitual. É interessante notar que Wittgenstein frequentemente analisa provas e argumentos com supostos resultados filosóficos da seguinte forma: usamos nossos conceitos de um modo tal e tal, em seguida procedemos com uma mudança nas regras, e dizemos então que descobrimos uma verdade filosófica, a qual consistiria justamente apenas nessa mudança gramatical, convenientemente "esquecida". Diante disso, Wittgenstein questiona: o que significa exatamente considerar que uma sentença é verdadeira no sistema, mas provada verdadeira fora do sistema? A seguinte passagem é ilustrativa desses questionamentos:

"Mas não podem existir proposições verdadeiras que são escritas nesse simbolismo, mas não são prováveis no sistema de Russell?" 'Proposições Verdadeiras', proposições que são verdadeiras em outro sistema, i.e., podem ser certamente afirmadas em outro jogo. Certamente, por que não deveriam existir semelhantes proposições; ou antes: por que proposições da física, e.g., não devem ser escritas no simbolismo de Russell? [sic.: proposições da física são verdadeiras, mas não prováveis no sistema] A questão é análoga a: podem existir proposições verdadeiras na linguagem de Euclides, que não são prováveis em seu sistema, mas que são verdadeiras? Porque existem proposições que são prováveis no sistema de Euclides que são falsas em outro sistema. Podem haver triângulos similares em outros sistemas que não tenham ângulos iguais. - "Mas isso é apenas uma piada, desde que eles não são similares no mesmo sentido" - Claro que não; e uma proposição que não pode ser provada no sistema de Russell é "verdadeira" ou "falsa" em um sentido diferente de uma proposição do Principia Mathematica. (RFM, I, III, 7)

Wittgenstein está dizendo aqui: se a sentença é verda- 
deira, mas não provada no sistema, é verdadeira em outro sentido que não o sentido inicial de ser verdadeira no sistema. Nessa passagem vemos que, para Wittgenstein, ou (1) a sentença verdadeira, mas não provada no sistema, é uma proposição empírica, que seria verdadeira por correspondência a algum fato, e não em virtude das regras do sistema, e, nessa suposição, se estaria tratando a sentença de Gödel como uma proposição contingente - como se esta pudesse também ser verdadeira por correspondência a algo (por algum critério externo ao sistema), e não em virtude das regras do sistema; ou (2) a sentença é verdadeira porque é provável em outro sistema, mas, nesse caso, não temos como manter que ela é verdadeira no sistema (ela seria verdadeira em outro sentido) ${ }^{4}$. Sendo ou não um bom argumento, Wittgenstein não precisa supor nenhuma tese antirrealista, precisa apenas fazer a suposição de que: 'não há verdade interna a um sistema sem critério de verdade interno a este mesmo sistema'. Aqui é interessante notar que 'ser verdadeira no sistema significa ser demonstrável no sistema ou ser um axioma deste' não é um pressuposto wittgensteiniano, mas é um pressuposto do próprio sistema do Principia Mathematica (PM). As proposições verdadeiras no sistema do PM são, e isso é expressamente estabelecido por Russell, as proposições primitivas (assumidas sem prova), e aquelas derivadas pelas regras de inferência do sistema (demonstradas) (Russell; Whitehead, PM, 402-406) - este é, portanto, o sentido primário de verdade estabelecido.

\footnotetext{
${ }^{4}$ Em uma interpretação alternativa, a sentença seria dita 'verdadeira' por expressar uma proposição verdadeira em outro sistema. Tal proposição não seria expressa no sistema em que a proposição é indemonstrável. Ela teria outro sentido no sistema em que é indemonstrável, pois ser provada confere outro sentido à sentença. Nessa abordagem, parecemos ficar com uma irredutivel pressuposição antirrealista.
} 
$\mathrm{O}$ ponto de Wittgenstein parece ser, portanto, que a aparência paradoxal que a internalização do predicado 'ser demonstrável' (Dem) parece gerar faz com que sigamos mudando nossos conceitos e separando a determinação da verdade do seu critério na interpretação da sentença como verdadeira, mas indemonstrável. Se dizemos que a sentença é verdadeira no sistema, embora demonstrada fora, aceita-se que a demonstrabilidade pode ser relativa ao sistema, mas a verdade não; o que seria, para Wittgenstein, supor uma verdade, e mesmo uma noção de sentido, sem critério de determinação interna ao sistema. Assim, para Wittgenstein, sem a ruptura da relação entre verdade e demonstrabilidade não se conseguiria estabelecer a leitura filosófica do resultado de Gödel, entretanto, aceitar esta ruptura já suporia o realismo e, desse modo, não seriam exatamente suas considerações que incorreriam em uma petição princípio.

Mas Wittgenstein vai, de fato, além, ele parece muitas vezes colocar em questão a legitimidade de o sistema internalizar um predicado relativo à sua própria demonstrabilidade. Certamente esse questionamento se relaciona à analogia que Wittgenstein faz da sentença de Gödel com um paradoxo lógico-semântico. A esse ponto voltamos adiante. Por enquanto, cumpre-nos notar apenas que, por mais estranho que esse questionamento possa parecer atualmente, Wittgenstein não foi o único a tecer comparações nesse sentido. A internalização do predicado relativo à 'demonstrabilidade' como tendo gerado uma forma de paradoxo por autorreferência foi questionada seriamente de modo muito mais contundente por Perelman (1936), e problematizada inclusive por Zermelo em sua correspondência com 
Gödel ${ }^{5}$. Se compararmos a diagonalização do predicado relativo à verdade no resultado de Tarski acerca da indefinibilidade da verdade, com a diagonalização do predicado relativo à demonstrabilidade na prova da incompletude de Gödel, vemos que as duas sentenças tem a mesma estrutura:

a) $\sim \operatorname{Tr}^{*}\left(\sim \operatorname{Tr}^{*}\right)$ é $\mathrm{V} \equiv \sim \operatorname{Tr}^{*}\left(\sim \operatorname{Tr}^{*}\right)$ não é $V$

b) $\sim \operatorname{Dem}^{*}\left(\sim \operatorname{Dem}^{*}\right)$ é $\mathbf{V} \equiv \sim \operatorname{Dem}^{*}\left(\sim \operatorname{Dem}^{*}\right)$ não é demonstrável

O predicado em negrito seria "meta" em relação ao predicado em itálico, e a aparência paradoxal surge porque tomamos o que é meta como no mesmo nível do formulado no sistema. Entretanto, com base nessa mesma forma, não dizemos que a demonstrabilidade do sistema também deveria ser formulada fora do sistema, mas, ao contrário, separamos a noção de verdade da noção de demonstração.

\section{A ANALOGIA COM OS PARADOXOS POR IMPREDICATIVIDADE E A QUESTÃO DA AUTORREFERÊNCIA INDIRETA}

Para Wittgenstein, transferindo a formalização aritmética para a metalinguagem Gödel não provaria a existência de verdades matemática indemonstráveis, mas mostraria apenas que, com tal formalização, determinadas construções não podem ser provadas ou refutadas:

\footnotetext{
5 "[...] your proof of the existence of undecidable propositions exhibits an essential gap. In order to produce an 'undecidable' proposition, you define... a class sign (a propositional function of one free variable) $S=R(q)$, and then you show that neither $[R(q)$; $(q)]=A$ nor its negation $\sim A$ would be provable. But does $S=\sim$ Bew $[R(n)$; $n$ ] really belong to your system?" (ZERMELO apud SHANKER 1989, 233)
} 
Vamos supor que demonstrei a indemonstrabilidade (no sistema de Russell) de P; então por essa prova provei P. Agora se essa prova fosse uma prova no sistema de Russell - devo nesse caso ter provado de uma vez que ela pertence e não pertence ao sistema de Russell. - Isso é o que fazem semelhantes sentenças. (RFM, A, III, 11)

Poderia ser dito: Gödel diz que se deve também ser capaz de confiar numa prova matemática quando se deseja concebê-la praticamente como a prova de que o padrão proposicional pode ser construído de acordo com as regras da prova? Ou: uma proposição matemática deve ser capaz de ser concebida como uma proposição de uma geometria que é realmente aplicável a si mesma. E, se se faz isso, isso implica que em certos casos não é possível contar com uma prova. (RFM, VII, 221)

Wittgenstein chega então a sugerir que deveríamos simplesmente desistir de interpretar a sentença aritmética como denotando a sentença metamatemática que a afirma 'indemonstrável':

'Mas certamente P não pode ser provável, desde que, supondo-se que fosse provada, então a proposição de que ela não é provável seria provada.' Ma se ela [P] fosse provada agora, ou se eu acreditasse talvez através de um erro - que a tivesse provado, por que não devo deixar a prova manter-se e dizer que devo suspender minha interpretação segundo a qual a sentença se afirma indemonstrável? (RFM, A, III, 10)

Essa analogia com os paradoxos por autorreferência é um dos pontos mais criticados da leitura que Wittgenstein faz de Gödel. Tal analogia não é, ela mesma, de modo algum equivocada, ao contrário, é largamente reconhecida. É o próprio Gödel $(1931,251)$ quem legitima essa associação na introdução da sua demonstração:

A analogia deste resultado com o paradoxo de Richard é evidente; existe também uma relação íntima com o paradoxo do mentiroso [nota: qualquer antinomia epistemológica pode ser usada para uma demonstração análoga de não-demonstrabilidade] uma vez que a proposição indecidível $[R(q) ; q]$ afirma que q pertence a $K$. i.e., de 
acordo com (1) que [R(q);q] não é demonstrável. Assim temos diante de nós uma proposição que afirma sua própria indemonstrabilidade.

Mas o que justifica a afirmação de que Wittgenstein não teria mesmo entendido a prova de Gödel é a consideração de que ele não teria notado que a sentença de Gödel não engendra nenhum paradoxo por autorreferência porque não contém uma circularidade viciosa. A autorreferência permitida pelo procedimento de aritmetização é uma autorreferência indireta. Sobre isso, afirma Shanker (1989, 222-223):

Supõe-se que Wittgenstein não compreendeu o teorema de Gödel porque Gödel não teve grandes problemas para tornar os vários níveis de enunciados que a prova emprega perspícuos (Gödel não escreve as P-sentenças [sentenças aritméticas], mas se refere a elas pelos números de Gödel, que não são eles mesmo escritos, mas são denotados por complexas funções para seu cálculo, que são também usadas para denotar as M-sentenças [meta-matemáticas] às quais correspondem.) É esta crítica das observações de Wittgenstein que, talvez, demande um escrutínio maior.

Como se sabe, o procedimento inicial de Gödel consiste em atribuir números de Gödel às fórmulas e provas do sistema, estabelecendo uma correspondência 1-1 entre expressões do cálculo e um subconjunto dos inteiros. A partir disso, enunciados metamatemáticos sobre expressões em um cálculo objeto são ao mesmo tempo lidos como enunciados sobre as relações aritméticas mantidas entre os números de Gödel correspondentes. Mas, para Wittgenstein, o mero mapeamento das sentenças pela numeração de Gödel em nada legitimaria o suposto espelhamento ${ }^{6}$ da metamatemática na matemática, que seria já, do seu ponto de vista,

\footnotetext{
' Retiramos o termo 'espelhamento' de Shanker, que o utiliza para ressaltar essa mesma distinção. Cf. Shanker (1989, 216-222).
} 
uma reformulação das regras do cálculo. Tal suposto espelhamento, de acordo com Wittgenstein, faria a sentença $G$ de Gödel mudar de regra, na medida em que assumiria que o conteúdo referencial da proposição de ordem superior poderia ser lido na proposição aritmética, o que permitiria a interpretação da sentença como dizendo algo de si mesma. $\mathrm{O}$ ponto consistiria em notar que o procedimento de correspondência proposto por Gödel seria apenas uma técnica de correlacionar números com expressões, mas que nada nesse procedimento autorizaria a interpretação da sentença como dizendo algo de si mesma. Vejamos a seguinte afirmação de Gödel (1931, 248-249):

Como é natural, para considerações matemáticas, não importa muito saber quais são os objetos que se tomam como símbolos primitivos e, para essa finalidade, usaremos os números naturais [nota: isto é, usaremos uma correspondência 1-1 entre os símbolos primitivos e os números naturais]. Assim, uma fórmula é uma sucessão finita de números naturais e a figura de uma demonstração é uma sucessão finita de sucessões finitas de números naturais. Deste modo, os conceitos metamatemáticos tornam-se conceitos sobre números naturais ou sucessões destes [nota] e por isso é pelos menos parcialmente exprimível no próprio simbolismo do sistema PM.

Pela correspondência, os números seriam tomados como símbolos como quaisquer outros. Mas, para Wittgenstein, isso em nada permitiria a conclusão de que conceitos metamatemáticos se tornassem conceitos sobre números, e, portanto, expressáveis no próprio sistema do PM. É apenas na medida em que os enunciados metamatemáticos sobre expressões são supostos espelhar e, por isso, ao mesmo tempo lidos como enunciados sobre relações mantidas entre os números de Gödel, que esses enunciados metamatemáticos são tomados como podendo falar de si mesmos indiretamente, isto é, não por meio da sua própria referência dire- 
ta, mas pelas relações anteriormente mencionadas.

Pelo procedimento de Gödel, ao invés de nos referirmos diretamente à sentença, descrevemos a sentença com uma função nome independentemente definida. Assim, a sentença poderia se referir a essa função independentemente definida enquanto fórmula sem, com isso, supor a si mesma já completa. Dessa forma, a sentença de Gödel escaparia à circularidade viciosa presente em sentenças como: 'esta sentença é falsa' ou (1) 'a sentença (1) tem 10 palavras'. Nesses casos, se tentamos substituir o 'esta' ou o '(1)' por sua referência, ficamos com algo assim: (1) A sentença 'a sentença 'a sentença 'a sentença ... $\infty$ tem 10 palavras. Mas esse regresso infinito não ocorreria na sentença de Gödel, o que Wittgenstein (2000, item $12183 \mathrm{v})$ teria falhado em notar:

Se entendermos o 'esta' como reflexivo aqui, então se poderia escrever a proposição simplesmente como uma abreviação para: A proposição: esta proposição... não se deixa demonstrar, e aqui o 'esta' não seria usado de modo reflexivo. A proposição seria uma proposição matemática sobre sua própria forma. [...] Esta proposição... não se deixa derivar: esta proposição... não se deixa derivar.

No caso em questão, estaríamos tentando falar de uma sentença na qual um dos seus termos, para referir, supõe a sentença inteira completa, mas a sentença precisa do termo (referindo) para completar-se, e o termo precisa da sentença completa para referir. Entretanto, isso não ocorreria com a sentença G. E é isso o que afirma Gödel $(1931,251)$ quando objeta em nota que sua sentença $G$ seja circular:

Ao contrário do que pode parecer, esta proposição não é circular, porque, em primeiro lugar, afirma a indemonstrabilidade de uma fórmula especificamente definida (exatamente a de ordem q na ordenação lexicográfica, depois de uma certa substituição) e, além disso, só depois (e como se fosse por acaso) se verifica que esta fórmula 
é exatamente aquela cuja indemonstrabilidade se exprime.

Mas Wittgenstein (2000, item 121 82v) está bastante consciente, ao contrário do que se poderia pensar, do caráter indireto da autorreferência da sentença de Gödel, afirmando que: "A sentença de Gödel diz de modo indireto que não é demonstrável”. Não obstante, para ele, ainda assim, deveríamos perguntar o que legitima tomar a fórmula independentemente definida como espelhando a sentença que afirma a indemonstrabilidade. Evitar a circularidade da sentença de Gödel significa dizer que tanto o sentido (1) da função-nome quanto o sentido (2) da sentença $G$ têm uma mesma referência (que permitiria ou justificaria o espelhamento de uma na outra), entretanto, o sentido da funçãonome seria determinado independentemente do sentido da sentença $G$ que, assim, poderia tomá-la como argumento enquanto fórmula, de tal modo que só depois, "como que por acaso", descobriríamos que o sentido 1 se refere à mesma proposição que o sentido 2. Entretanto, o que significa dizer que o sentido 1 e o sentido 2 (meta em relação a 1) tem uma mesma referência? Comentando esse ponto, Rupert Read $(2005,11)$ afirmou, de maneira muito mais direta que Wittgenstein:

Vamos por todos os meios permitir que a seta do 'esta' volte para si mesma passando através de vários estágios intermediários, e seguindo uma longa e desviante trajetória, antes de retornar para seu alvo. Mas por que isso deve nos convencer do que quer que seja? Por que deve fazer qualquer diferença para a lógica da situação se a seta que traçamos é longa ou curta?

ponto é: a sentença de Gödel precisa se referir à fórmula na medida em que esta se refere à sentença, ainda que indiretamente; de outro modo, deveríamos suspender a interpretação da sentença como se dizendo indemonstrável. 


\section{A INTERPRETAÇÃO DE FLOYD E PUTNAM}

A afirmação de que 'deveríamos então suspender a interpretação da sentença como se dizendo indemonstrável' é também central para a leitura que Juliet Floyd e Hilary Putnam propõem das observações de Wittgenstein sobre o teorema de Gödel. No artigo "Uma nota sobre o notório parágrafo de Wittgenstein sobre o teorema de Gödel” é apresentada uma arrojada interpretação da passagem A, III, 8, dos RFM, que citamos em seguida, de acordo com a qual ficaria garantido que Wittgenstein, apesar de tudo, teria entendido a prova de Gödel e, além disso, avançado uma observação de notório interesse filosófico sobre este:

Imagino alguém pedindo o meu conselho; ele diz: "eu construí uma proposição (usarei 'p' para designá-la) no simbolismo de Russell, e por meio de certas definições e transformações, pode ser interpretada de tal modo que ela diga: 'P não é demonstrável no sistema de Russell'. Não devo dizer que esta proposição por um lado é verdadeira, e por outro é indemonstrável? Pois, admitindo que ela seja falsa, então é verdade que ela é indemonstrável. E isso não pode ser! E se ela for demonstrada, então isso mostra que ela não é demonstrável. Assim, ela só pode ser verdadeira, mas indemonstrável." Tal como perguntamos 'demonstrável em que sistema?', então também temos que perguntar 'verdadeiro em que sistema?' 'Verdadeiro no sistema de Russell' significa, como dissemos, demonstrado no sistema de Russell, e 'falso no sistema de Russell' significa que se demonstrou o contrário no sistema de Russell. - Agora, o que é que o seu 'suponha que é falsa' significa? No sentido de Russell, significa 'suponhamos que o contrário é demonstrado no sistema de Russell'; se essa é a sua suposição você desistirá da interpretação segundo a qual ela é indemonstrável. E por 'esta interpretação' eu entendo a tradução da proposição nesta proposição inglesa. - Se admitir que a proposição é demonstrável no sistema de Russell, isso significa que ela é verdadeira no sentido de Russell, e terá novamente de desistir da interpretação 'P não é demonstrável'. Se admitir que a sentença é verdadeira no sentido de Russell, a conseqüência é a mesma. Além disso: se é suposto que a proposição é falsa num outro sentido que não o de Rus- 
sell, então não contradiz o fato de que ela seja demonstrada no sistema de Russell. (O que no xadrez significa 'perder', pode determinar a vitória num outro jogo.) (RFM, I, Ap III, 8, grifos meus)

De acordo com Floyd e Putnam, a passagem anterior conteria uma afirmação filosófica de grande interesse, sendo esta a afirmação que os autores tomam como tendo tal interesse na passagem: 'se se assume que ' p' é provável no sistema de Russell deve-se (ou se irá presumivelmente) desistir da tradução de $\mathrm{P}$ pela sentença em inglês $\mathrm{p}$ não é provável'. De acordo com Floyd e Putnam, tal afirmação deve ser explicada da seguinte forma: se se assume que não-G é provável no sistema de Russell, deve-se desistir da tradução de $G$ pela sentença ' $G$ não é provável', porque se não-G fosse provável no PM, o PM seria ômega-inconsistente, e se o PM fosse ômega-inconsistente, não daria conta da noção de número natural, e não poderíamos mesmo, portanto, traduzir $G$ como 'G não é provável no $P M$ ' porque o predicado ' $x$ é um número natural' em $G$ não poderia ser interpretado como x é um número natural - e seria isso o que Wittgenstein teria pretendido dizer.

Vejamos então o argumento completo e expliquemos o que Floyd e Putnam estão atribuindo a Wittgenstein para avaliarmos em que medida é plausível que Wittgenstein tenha pensado isso. Primeiramente, o que significa o sistema ser ômega-inconsistente? Um sistema é entendido como ômega-inconsistente se existe uma fórmula a qual provamos todas as suas instâncias particulares, mas não o universal. Ou, se existe uma fórmula que é demonstrável, mas não é demonstrável em nenhum estágio, isto é:

$\forall \mathrm{n} \in \mathrm{N}, \mathrm{A}$ fórmula $\mathrm{F}$ não é demonstrável no estágio n: $\{\sim \operatorname{Dem} 1(\mathrm{~F}) ; \sim \operatorname{Dem} 2(\mathrm{~F}) ; \sim \operatorname{Dem} 3(\mathrm{~F}) ; \ldots\}$. Mas $F$ é dem: 
$\{\operatorname{Dem}(\mathrm{F}) ; \sim \operatorname{Dem} 1(\mathrm{~F}) ; \sim \operatorname{Dem} 2(\mathrm{~F}) ; \sim \operatorname{Dem} 3(\mathrm{~F}) ; \ldots\}$

Ou, de modo mais geral:

$\vdash \exists \mathrm{x}(\mathrm{x}) \& \forall \mathrm{n} \in \mathrm{N} \vdash \sim \mathrm{F}(\mathrm{x})$

Assim, teríamos que supor poder construir um modelo que ultrapassa os naturais, ou seja, que o sistema não tem nenhum modelo no qual o predicado interpretado como ' $\mathrm{x}$ é um número natural' possua uma extensão isomórfica à dos números naturais.

A suposição de ômega-consistência, no resultado de Gödel, substitui a suposição mais forte da correção do sistema, interditando que a negação de $G$ possa ser provada. Se $G$ fosse provada, o sistema seria inconsistente. Se não-G fosse provada, o sistema seria ômega-inconsistente. É, portanto, supondo-se o sistema consistente e ômega-consistente que o resultado de Gödel se segue. Essas são suposições sintáticas, isto é, dizem respeito apenas à demonstrabilidade e à indemonstrabilidade, não falam em verdade ou falsidade. Uma maneira mais pesada, por assim dizer, de se garantir que $G$ não poderia ser provada falsa no sistema seria supondo-se a correção do sistema, isto é, que o sistema não prova nada falso. Desse modo, se $G$ fosse provada falsa, deveria ser provável no sistema (pois se afirma indemonstrável), contrariando a correção. Como quer que seja, a correção implica a ômega-consistência porque se tudo que provamos for verdadeiro no modelo, então não pode existir uma sentença $\mathrm{F}(\mathrm{x})$ provada no sistema, e para todo $n$ pertencente aos naturais, provarmos no sistema ' $\sim \mathrm{F}(\mathrm{n})$ ', afinal só provamos o que é verdadeiro no modelo. Adicionalmente, se tivermos provado não-G (isto é: que não é o caso que 
G é indemonstrável e, portanto, $G$ seria demonstrável), isso não poderia ser o caso se o sistema fosse ômega-consistente e, portanto, o sistema seria ômega-inconsistente. Mas, por que exatamente? Porque se $\mathrm{G}$ é refutado, não é o caso que $\mathrm{G}$ é indemonstrável e, por isso, a demonstração de $\mathrm{G}$ deveria ser demonstrável. Isso se deve em grande medida ao caráter autorreferente da sentença. Mas, se o sistema é ômega consistente, e ' $\sim G$ ' é demonstrado, sendo, então, $G$ refutado, segue-se que a demonstração de $G$ não poderia ser jamais demonstrada. Assim, o sistema seria ômega-inconsistente.

De fato, isto (se provamos $\sim G$, o sistema tem que ser ômega-inconsistente) se segue da própria diagonalização do predicado relativo à demonstrabilidade. Para ver isso, basta seguir os seguintes passos:

1) Se considerarmos que a negação de uma sentença qualquer é refutável se,, e somente se, a sentença é demonstrável:

$\sim \mathrm{F}(\mathrm{x})$ é ref. $\leftrightarrow \mathrm{F}(\mathrm{x})$ é dem.

2) E para aplicarmos isso à diagonalização da demonstrabilidade, temos que:

$\sim \operatorname{Dem}^{*}(\mathrm{x})$ é ref. $\leftrightarrow \operatorname{Dem}^{*}(\mathrm{x})$ é demonstrável

Dem $(\mathrm{x}(\mathrm{x}))$ é demonstrável

3) Aplicando isso à sentença de Gödel, isto é, à sentença que afirma de si mesma que não é demonstrável, temos que: 
$\sim \operatorname{Dem}^{*}\left(\sim \operatorname{Dem}^{*}\right)$ é refutável $\leftrightarrow \operatorname{Dem}^{*}\left(\sim \operatorname{Dem}^{*}\right)$ é demonstrável
|
$\operatorname{Dem} \underline{\left(\sim \operatorname{Dem}^{*}\left(\sim \operatorname{Dem}^{*}\right)\right)}$ é de-
monstrável
G é refutável
$\leftrightarrow$ Dem
G é demonstrável

4) Ora, mas se G é refutável, temos que

$\vdash \sim G$, o que significa que

ҰG G mas 5) se cruzarmos isso agora com a suposição da ômega-consistência temos uma contradição, porque teríamos que :

$\forall \mathrm{n} \in \mathrm{N}, \mathrm{G}$ não seria demonstrável no estágio $\mathrm{n}$, e, portanto, $\forall$ Dem $(G)$

6) Das fórmulas anteriores retiramos uma contradição

(Dem ( G ) é demonstrável) \& ( $\nvdash$ Dem $(G))$

7) Desse modo, a suposição de ômega-consistência deve ser negada, sendo o sistema ômega-inconsistente.

A interpretação de $\mathrm{G}$ como se dizendo indemonstrável teria então que ser suspensa, no caso de a negação de $\mathrm{G}$ ser demonstrada, justamente porque a noção de número natural não poderia ser expressa no sistema, dada a sua ômegainconsistência: a ômega-inconsistência mostra que um sistema não tem nenhum modelo no qual o predicado interpretado como ' $x$ é um número natural' possua uma 
extensão isomórfica a dos números naturais. Isso se explica na medida em que a sentença $G$ tem a forma: $\sim \exists x$ Número natural $(\mathrm{x})$ \& Prova $(\mathrm{x}, \mathrm{t})$, onde $\mathrm{t}$ abrevia uma expressão numérica cujo valor resulta no número de Gödel de $\mathrm{G}$ ela mesma. Entretanto, afirmam Floyd e Putnam (2000, 625):

[...] descobrindo que o PM é ômega-inconsistente, descobrimos que: 1. 'número natural' não pode ser assim interpretado. Em todas as interpretações admissiveis do PM (todas as interpretações que se ajustem a ao menos um modelo do PM), existem entidades que não são números naturais (e, portanto, não são números de Gödel de provas); 2) aqueles predicados do PM (e.g. Prova $(\mathrm{x}, \mathrm{t}))$ cujas extensões são provavelmente infinitas e que acreditamos ser subconjuntos infinitos de $\mathrm{N}$ (o conjunto dos números naturais), não tem tais extensões em qualquer modelo. Ao contrário, eles têm extensões que invariavelmente também contém elementos que não são números naturais; 3) em resumo, a tradução de $\mathrm{P}$ como $\mathrm{P}$ é indemonstrável no PM é insustentável nesse caso - exatamente como Wittgenstein afirmou! Isso, como quer que seja, não afeta a correção da prova de Gödel, pois nada na prova diz respeito a tal interpretação em prosa ordinária.

Essa leitura das observações de Wittgenstein, apesar de elegante, não parece muito plausível porque é pouco provável que Wittgenstein tenha condensado esse argumento naquelas duas linhas. Afinal, se esse era o mais importante de seus comentários sobre Gödel, ele deveria ter escrito mais sobre o assunto. A interpretação, ainda assim, parece corroborar-se por relatos de cunho biográficos, dentre os mais importantes a afirmação categórica de Goodstein, em 1957, de acordo com a qual Wittgenstein teria interpretado o teorema de Gödel imediatamente como tendo estabelecido a ômega-inconsistência do sistema formalizado em questão, bem como a sua consequente impossibilidade de captar o conceito de número natural; e a afirmação de Alister Watson, em seu artigo sobre a capacidade de sistemas re- 
cursivos aritméticos ômega-inconsistentes expressarem a noção de número natural, no qual ele afirma ter chegado a essa ideia conversando com Wittgenstein e com Turing (cf. Floyd; Putnam 2000, 626).

De fato, ainda que a questão da ômega-inconsistência tenha sido notada por Wittgenstein, isso não significa que ele a tomava como a questão de cunho filosófico mais importante a ser ressaltada no que se refere ao teorema, de outro modo, parece que ele mesmo teria desenvolvido em detalhes esse ponto. É textual que Wittgenstein certamente chega ao caráter paradoxal do passo (3) anteriormente exposto, e certamente o associa com os paradoxos por autorreferência. Parece também que isso é razão suficiente para ele propor a recusa à interpretação da sentença como se dizendo indemonstrável. Em todo caso, é razoável que Wittgenstein tenha chegado a relacionar isso com a ômegainconsistência, inclusive porque, como notamos, a ômegainconsistência que se segue de $\sim \mathrm{G}$ é uma consequência da própria diagonalização do predicado, o que Wittgenstein certamente leva em conta. Aliás, se Watson diz que chegou a essa ideia conversando com Wittgenstein, não temos mesmo razão para supor que ele mente. Obviamente isso ajuda a argumentar que Wittgenstein deve ter compreendido a prova de Gödel, se foi, afinal, capaz de pensar e formular algum raciocínio amplamente entendido como correto sobre esta.

Mas, tal como entendemos, a leitura defendida por Floyd expressa corretamente o ponto da posição de Wittgenstein justamente na medida em que entendemos a ômega-inconsistência do sistema, e a derivada impossibilidade do predicado 'x é um número natural' ser lido neste, como se originando da diagonalização da sentença G. Isto 
é: a leitura é interessante quando entendemos o resultado das análises propostas como se derivando da exigência de que enunciados metamatemáticos espelhem enunciados aritméticos. $\mathrm{O}$ ponto central seria, portanto, trivial, e isso explica porque Wittgenstein não escreveu mais sobre a questão da ômega-inconsistência, como teria feito depois, influenciado pelas suas análises, Alister Watson. São resultados como este que os paradoxos por impredicatividade têm gerado desde a aparição no programa logicista. Permitir que a sentença, por meio da função-nome, diga algo sobre si mesma deve implicar tomar enunciados de ordem superior como sendo objetivados pelos mesmos referentes abstratos que enunciados de ordem inferior. Isso implica necessariamente tomar o domínio dos objetos abstratos como impredicativo. Por isso, em meio aos seus comentários sobre Gödel, Wittgenstein (2000, item 121 76v) afirma: "A Filosofia deve à Teoria de Conjuntos uma enormidade, pois agora temos uma experiência das armadilhas que a fraseologia pode apresentar [...]”. Se for assim, devemos suspender a interpretação (em prosa) da sentença como dizendo algo de si, e daí também Wittgenstein afirmar que se tomamos a sentença como verdadeira no sentido de Russell, no PM, a mesma conclusão se segue. Deixando isso claro, acreditamos ressaltar a coerência da leitura de Floyd e Putnam com as demais passagens de Wittgenstein sobre o tema.

O que a descrição da sentença, pela função nome, faz é conferir-lhe um sentido, e, nesse caso, teríamos dois sentidos, que deviam ser ambos relativos à mesma proposição. Do mesmo modo, então, que perguntamos em que sentido a sentença indecidível dentro do sistema é a mesma provada verdadeira fora, podemos perguntar agora, com 
Wittgenstein, em que sentido a sentença meta, que afirma a indemonstrabilidade, e a sentença aritmética da qual a indemonstrabilidade é afirmada podem ser ditas proposições que espelham uma a outra. Como afirma Wittgenstein, parece que devemos ter duas proposições - 'P' e 'P é indemonstrável' -, e não temos como justificar a asserção de que se tratam da mesma proposição?. Shanker (1989, 224) também comenta esse ponto:

A aparência ilusória da conclusão em prosa paradoxal de que uma proposição matemática pode inteligivelmente dizer de si mesma que é indemonstrável funda-se na premissa de que se pode distinguir entre U [enunciado aritmético] e Mi [enunciado meta-matemático] e tratá-las como proposições matemáticas autônomas mapeadas uma sobre a outra, e então argumentar adicionalmente que as estruturas de U e Mi são tais que espelham uma a outra.

E é esse espelhamento que Wittgenstein problematiza. Obviamente, dizendo isso, não estamos mantendo aqui que seja um problema em si mesmo para, segundo Wittgenstein, a autorreferência da sentença de Gödel. $\mathrm{O}$ problema é o que se pretende com essa permissão. Wittgenstein, no período tardio de sua filosofia, não interdita a atribuição de sentido às proposições que envolvem alguma forma de impredicatividade (autorreferência). Ao contrário, ele afirmou: "Poderíamos introduzir um jogo de linguagem no qual proposições que dizem algo sobre si mesmas encontram aplicação" (Wittgenstein 2000, item 121 79v). Mas é preci-

\footnotetext{
7 “O que significa dizer que 'P' e 'P é indemonstrável' são a mesma proposição? Significa que essas duas sentenças em inglês tem uma mesma expressão em tal e tal notação" (RFM, I, III, 9) Mas o fato de que elas têm uma mesma expressão em alguma notação, não as torna a mesma proposição, desde que "a expressão sozinha não significa nada", como notou Wittgenstein no Tractatus (3.3323) "Suponhamos, pois, que a função $\mathrm{F}(\mathrm{fx})$ pudesse ser seu próprio argumento: haveria, nesse caso, uma proposição ' $F(F(f x))$ ', e nela a função externa $F$ e a função interna $F$ devem ter significados diferentes: pois a interna tem a forma $\Phi(\mathrm{fx})$, a externa, a forma $\Psi(\Phi(\mathrm{fx}))$. Ambas as funções têm em comum apenas a letra ' $f$ ', que sozinha, porém, não designa nada. [...]" (TLP, 3.333)
} 
so, de um ponto de vista afim com o método wittgensteiniano, clarificar o que está envolvido nessa atribuição de sentido, e o que decorre da mesma, na medida em que, nesses casos, não é possível contar com nenhuma suposta referência, ou critério, existente independentemente determinando o sentido da proposição. De um ponto de vista wittgensteiniano, como nossas explicações têm um fim em algum lugar, a própria determinação semântica envolve alguma ausência de critérios externos de determinação ulterior, e, nesse sentido, uma forma de impredicatividade é mesmo uma característica geral do âmbito normativo da linguagem: "Se poderia dizer também que a proposição aritmética $3+2=5$ afirma algo de si mesma. Ela poderia ser desmembrada em um grupo de 3 e um grupo de 2 signos?" (Wittgenstein 2000, item 124 89). Lembrar-nos disso é também uma importante função dos paradoxos por impredicatividade: "As várias formas quase piadistas do paradoxo lógico são de interesse apenas até lembrarem alguém do fato de que uma forma séria do paradoxo é indispensável para entendermos sua função" (RFM, VII, 30). O problema é se pretender aceitar o sentido de uma sentença autorreferente, sem mais modificações em nossos conceitos, como se esta pudesse continuar a ter sua verdade determinada externamente, por uma referência independente, tal como uma proposição empírica. Do ponto da vista da Filosofia, segundo Wittgenstein, se pode atribuir um sentido às sentenças autorreferentes, do mesmo modo que as proposições normativas podem também possuir sentido, mas, para isso, é preciso que estas tenham um uso e se insiram em uma prática bem determinada, que lhes confira significabilidade e função, anulando a vacuidade de sentido da proposição:

Muito embora "a classe dos leões não é um leão" pareça uma sen- 
tença sem sentido, a qual se pode apenas atribuir um sentido por delicadeza, eu ainda não quero tomá-la dessa forma, se isso é apenas tomado como certo (e não como no Tractatus). Assim minha concepção é diferente aqui. Isso significa que estou dizendo agora: existe um jogo de linguagem com esta sentença também. (RFM, VII, 36)

Entretanto, não é claro que possamos ter isso no suposto âmbito da metamatemática:

Aqui é necessário lembrar que as proposições da lógica são construídas como não tendo nenhuma aplicação como informação na prática. Então, se poderia muito bem dizer que elas não são proposições de todo; e que a escrita delas encontra-se sob a necessidade de justificação. Agora se nós juntamos a estas proposições uma estrutura adicional, como uma sentença, então, estamos mais no escuro sobre que tipo de aplicação este sistema de combinações de signos é suposto ter; desde que o meramente envolver uma sentença não é suficiente para fornecer a esta conexão de signos qualquer significado. (RFM, A, III, 20, p.123)

Não se tem, acima de tudo, o menor uso para tal sentença. (Wittgenstein 2000, item 121 81v)

$\mathrm{Na}$ aritmética formal, a permissão da autorreferência aparece apenas, portanto, como uma permissão de um lance distinto em um jogo de linguagem, tentando ser entendida ainda sob a manutenção parcial das regras que a interditariam, e é só por isso, por essa manutenção parcial, que ainda acredita-se poder ter critérios externos para a determinação da verdade da sentença $G$.

\section{UM PROBLEMA PARA O PROGRAMA DE HILBERT}

De fato, as próprias análises de Wittgenstein se coadunam com a ideia geral, atribuída ao resultado de Gödel, de que um sistema não possa ser usado para provar sua própria consistência, desde que seria preciso sair deste para isso. Particularmente, dadas as críticas que Wittgenstein faz ao 
programa de Hilbert, parece que ele deveria ser simpático a esta leitura intuitiva da prova de Gödel.

Pode ser mostrado, entretanto, que o principal problema que Wittgenstein identifica na prova Gödel teria suas raízes já no programa de Hilbert, na aceitação da demanda de que a linguagem matemática dê conta formalmente de seus próprios fundamentos, o que se relaciona diretamente com o já mencionado suposto espelhamento dos enunciados metamatemáticos, acerca da demonstrabilidade em S, em enunciados aritméticos, que são eles mesmos parte de $\mathrm{S}$. De acordo com Wittgenstein, Hilbert demanda justificação para além do que é possível obter. Lembremos aqui então a muito citada exasperação de Hilbert diante da aparente quebra de confiança que os paradoxos acarretariam para a matemática:

A situação na qual nós presentemente nos encontramos com respeito aos paradoxos é ao final das contas intolerável. Apenas pense: na matemática, este modelo perfeito de confiança e verdade, as várias noções e inferências, como todos aprendemos, ensinamos e usamos, levam às absurdidades. E onde mais encontraríamos confiança e verdade, se mesmo o pensamento matemático falhasse? (Hilbert 1925, 375)

Mas é realmente possível que a matemática esteja toda em risco? Parece que queremos uma prova de consistência para fundamentar aquilo que já confiamos. E o problema de princípio envolvido nessa tarefa é que, se a matemática provar sua própria consistência, isso não pode ser razão para confiarmos nela, pois apenas aceitamos a prova de consistência porque já a supomos consistente, ou melhor, já confiamos cegamente na prova:

Mas espere - não é claro que ninguém queira encontrar uma contradição? E então se eu mostrasse a alguém a possibilidade de uma 
contradição, ele faria tudo para torná-la impossível? (E se não fizesse isso, seria um 'cabeça de vento'.) Mas suponha que ele respondesse: "não posso imaginar uma contradição em meu cálculo. - Você me mostrou uma contradição em outro, mas não nesse. Nesse, não existe nenhuma, nem sequer posso ver a possibilidade de uma." "Se minha concepção do cálculo vier a se alterar; se seu aspecto mudar por causa de algum contexto que não posso ver agora - então falarei algo mais sobre isso." "Não vejo a possibilidade de uma contradição [em meu cálculo]. Não mais do que você - como parece - vê a possibilidade de existir uma em sua prova de consistência." (RFM, III, 88)

A confiabilidade na matemática deve ser fulcral, isso significa dizer que ela não está realmente em questão, mas é suposta para que a própria prova seja aceita e, nesse sentido, a prova de consistência perde seu sentido, pois, em máximo grau, estaríamos provando algo que já supomos e que não pode, portanto, ser provado, mas precisa sempre ser tomado como necessário:

Se tenho medo de que alguma coisa possa em algum momento ser interpretada como a construção de uma contradição, então nenhuma construção pode tirar este medo indefinido de mim. A cerca que coloco ao redor da contradição não é uma meta-cerca. Como uma prova pode tornar o cálculo certo em princípio? Como ele poderia ter falhado em ser um cálculo próprio a menos que essa prova tivesse sido encontrada? (RFM, III, 87)

A própria demanda pela prova de consistência aparece, assim, como desprovida de propósito, posto que já supõe que tomamos o cálculo no qual a prova é feita como certa, indubitável - isso mostra que nós mesmos não levamos a sério o suposto perigo das contradições como interditando nossa prática matemática, como devendo nos fazer jogá-la fora, mas, se já temos que confiar no cálculo para que a própria demanda da prova de consistência faça sentido, se já confiamos então no cálculo cegamente, por que precisamos da prova? A prova não poderia fornecer a confiança úl- 
tima que buscamos (uma que não seria cega, mas fundamentada), afinal, a prova de consistência é feita na própria matemática, e se a inconsistência é um risco, por que não afetaria a própria prova? Como poderíamos então confiar na própria prova de consistência? Se a matemática for inconsistente, ela mesma não será inválida? ${ }^{8}$ Afinal, se supomos o sistema inconsistente, e a regra da trivialidade, qualquer sentença poderia ser provada, inclusive a que afirma a consistência do sistema. Dessa forma vemos que, se o sistema for inconsistente, ele provará sua consistência, e, portanto, tal prova não pode ser razão suficiente para a consistência. De outro modo, estaríamos agindo como alguém que confia no mentiroso porque ele afirma que não mente. Ora, mas é evidente que, se ele mente, isso também é uma mentira, da mesma forma que, se a matemática fosse já inconsistente, sua consistência seria um teorema.

O problema que Wittgenstein vê na prova de Gödel estaria já primariamente em aceitar como legítima a demanda, por princípio impossível, erguida pelo programa de Hilbert (apud SHANKER 1989, 184):

Tudo que constitui a matemática hoje é rigorosamente formalizado, então esta se torna uma pilha de fórmulas... À matemática ordinária, então formalizada, é adicionada uma, em certo sentido, nova matemática, uma metamatemática. [...] Nessa metamatemática trabalha-se com as provas da matemática ordinária, essas últimas, elas mesmas, formam o objeto de investigação.

Mas qual o problema geral aqui? A metamatemática teria que ser matemática ainda, e, portanto, não poderia fazer

\footnotetext{
${ }^{8}$ De fato, este é também o cerne da crítica de Poincaré à fundamentação da matemática com provas de consistência, na medida em que o filósofo mantém que tal fundamentação incorreria em circularidade por precisar se referir a todas as provas do sistema e, ao mesmo tempo, empregar provas, não podendo, assim, justificar a indução matemática.
} 
o que se propõe:

Se as contradições em matemática começam através de uma falta de clareza, nunca posso dissipar esta falta de clareza por uma prova. A prova apenas prova o que ela prova. Mas ela não pode superar a névoa. Isso mostra por si mesmo que não pode existir tal coisa como uma prova de consistência (se pensamos as inconsistências da matemática como sendo do mesmo tipo que as inconsistências da teoria de conjuntos), que a prova não pode começar a oferecer o que queremos dela. Se não estou certo sobre a natureza da matemática, nenhuma prova pode me ajudar. E se eu estou certo sobre a natureza da matemática, a questão da consistência sequer começa. $(P R, 320)$

Isso é fundamental para entender o que Wittgenstein afirma sobre a interpretação filosófica da prova de Gödel: a prova não pode superar a névoa filosófica, ela apenas prova o que ela prova, não garante nada sobre a natureza da matemática. Na medida em que Hilbert espera que a matemática prove sua própria razoabilidade, parece perguntar pela "possibilidade absoluta" - o que seria, para Wittgenstein (problema por ele enfrentado desde o Tractatus), um contrassenso:

Não posso traçar os limites de meu mundo, mas posso traçar limites no interior de meu mundo. Não posso perguntar se a proposição $p$ pertence ao sistema $\mathrm{S}$, mas posso perguntar se ela pertence à parte de S. Desse modo, posso determinar o lugar da trissecção de um ângulo dentro do sistema maior, mas não posso, dentro do sistema euclidiano, perguntar se ele é solúvel. Em que linguagem deveria eu perguntar isso? Na euclidiana? Mas tampouco posso perguntar na linguagem euclidiana sobre a possibilidade de bissectar um ângulo dentro do sistema euclidiano. Pois, nessa linguagem, isso levaria a perguntar pela possibilidade absoluta e uma tal pergunta é sempre um contra-senso. (PR, 152)

Entretanto, isso não significaria, para Wittgenstein, que, por outro lado, a consistência absoluta poderia ser provada satisfatoriamente em um metassistema, por assim 
dizer, desde que, por um lado, a questão obviamente retornaria para esse suposto metassistema, e, ainda teríamos que justificar a relação entre sistema e metassistema:

Mas aqui nada há a ser encontrado que pudéssemos chamar de hierarquia de tipos. Na matemática, não podemos falar de sistemas em geral mas somente de sistemas dentro de sistemas. Eles são justamente aquilo sobre o que não podemos falar. E, portanto, também aquilo que não podemos procurar. [...] Suponhamos agora que tenho dois sistemas: não posso peguntar por um sistema que abarque os dois, já que não somente sou incapaz agora de procurar esse sistema como, mesmo no caso de surgir um sistema que abarque dois sistemas análogos aos originais, percebo que nunca poderia ter procurado por ele. $(P R, 152)$

Assim, não é suficiente dizer que p pode ser provada; o que devemos dizer é: pode ser provada segundo um sistema determinado. Além disso, a proposição não afirma que $\mathrm{p}$ é provável no sistema $\mathrm{S}$, mas no seu próprio sistema, o sistema de $\mathrm{P}$. A pertinência de $\mathrm{p}$ ao sistema $S$ não pode ser afirmada, mas tem de mostrar a si mesma. Não se pode dizer que $\mathrm{p}$ pertence ao sistema $\mathrm{S}$; não se pode perguntar a qual sistema $\mathrm{p}$ pertence; não se pode procurar pelo sistema de $\mathrm{p}$. Entender $\mathrm{p}$ significa entender seu sistema. Se $\mathrm{p}$ parece passar de um sistema a outro, então $p$, na realidade, mudou de sentido. $(P R, 153)$

Essas passagens são particularmente significativas para entender as observações de Wittgenstein que expomos anteriormente. Apenas sob esse ponto de vista, entendendo suas razões, podemos compreender a recusa a aceitar que uma mesma proposição possa ser indemonstrável em um sistema e demonstrável em outro. De fato, Hilbert procurou diferenciar dois usos da indução matemática, um uso conceitual e outro formal (cf. Hilbert 1927, 471-472). Não precisaríamos, assim, garantir pelo método indutivo a própria indução matemática. Tal possibilidade se funda na distinção geral de Hilbert entre proposições algébricas - ideais - e proposições conteudísticas - reais - da matemática. As 
proposições conteudísticas seriam formalizadas produzindo proposições ideais, metamatemáticas, que poderiam ser aplicadas em domínios inesperados. Mas a consistência das proposições conteudísticas é suposta estar garantida intuitivamente, e, com base nestas, poderíamos fundar, então, a consistência da matemática em geral, reduzindo as verdades da aritmética superior ao que é providenciado pela intuição. Assim, a matemática é dividida, por Hilbert, em (A) uma parte real, intuitiva, e (B) uma parte ideal, formal e sem conteúdo. A parte intuitiva seria um subconjunto da parte formal, mas a consistência da parte real é tomada como garantida e é a partir desta que a parte B seria formalizada, para que, assim, em B, fosse provada a consistência de $A+B$. Esta é uma distinção que Wittgenstein não aceita (cf., e.g., PR, XIII, 150). A parte ideal precisaria obedecer, de acordo com Wittgenstein, aos mesmos princípios do que é real para que a fundamentação funcionasse - o que significa também dizer que o formal já deveria estar dado com o conteudístico. Estaríamos, portanto, supondo A como certa, e - na medida em que $B$ obedece aos mesmos princípios que $A$ - também estaríamos, para provar a correção de $A+$ $B$, supondo $B$ como certa. Ora, se os princípios de $B$ são os mesmos de $\mathrm{A}$, quando provamos $\mathrm{A}+\mathrm{B}$, em $\mathrm{B}$, estamos garantindo esses princípios por eles mesmos (ou melhor, não os estamos garantindo). O que ocorreria, de acordo com Wittgenstein, seria, primeiro, uma separação entre o âmbito real e o âmbito ideal, e, depois, a junção destes novamente, para que um pudesse garantir o outro. Mas, ou bem eles se separam, e não conseguem mais fundamentar um ao outro, ou já estão sempre juntos, e a fundamentação é impossível. Hilbert supõe que as proposições formais seriam desprovidas de sentido, de conteúdo, mas, se é assim, como 
elas se relacionam como as supostas proposições conteudísticas? Parece mais razoável pensar que já estão sempre relacionadas, mas isso significa exatamente manter que não há qualquer fundamentação possível:

A meta-matemática de Hilbert deve ser mostrada ser matemática disfarçada. (WCV, 136)

O que Hilbert faz é matemática e não meta-matemática. É outro cálculo, exatamente como qualquer outro. (WCV, 121)

Posso jogar com as peças de xadrez de acordo com certas regras. Mas também posso inventar um jogo no qual jogo com as regras elas mesmas. As peças em meu jogo são agora as regras do xadrez, e as regras do jogo, são, digamos, as leis da lógica. Neste caso tenho ainda um outro jogo, e não um meta-jogo. $(P R, 319)$

Basicamente, o ponto de Wittgenstein é: qualquer suposto metacálculo é, no final das contas, apenas cálculo e, por isso mesmo, não pode fundamentar o cálculo em geral:

O que é uma prova da provabilidade? É diferente da prova da proposição? E uma prova da provabilidade talvez seja a prova de que uma proposição tem sentido? Mas, então, tal prova teria de se basear em princípios inteiramente diferentes daqueles em que a prova da proposição se baseia. Não pode haver uma hierarquia de provas. Por outro lado, não pode haver, em nenhum sentido fundamental, algo como uma metamatemática. Tudo tem de ser de um tipo (ou, o que dá no mesmo, de nenhum tipo). (PR, 153)

Então, o que dizer da prova de Gödel? Gödel teria cometido o mesmo engano de Hilbert na medida em que aceitou a sua demanda como tendo sentido, acreditando poder provar matematicamente sua impossibilidade. Mas, embora a demanda seja impossível e sem sentido, a prova de sua impossibilidade, nesse caso, também o é - o problema estaria, para Wittgenstein, como sempre, já em aceitar a questão. Segundo Wittgenstein, Gödel responde Hilbert 
aceitando que a matemática poderia ser metamatemática. Por isso também ele afirma que a sentença de Gödel tem a pretensão de ser uma sentença matemática sobre sua própria forma (cf. Wittgenstein 2000, item 12183 v). Com isso, Gödel estaria também acreditando provar uma verdade filosófica:

[...] o desenvolvimento da matemática, no sentido de uma maior exatidão, conduziu à formalização de vastos domínios desta ciência, de modo a que as demonstrações possam ser efetuadas de acordo com algumas regras mecânicas. [...] Como é natural, para considerações matemáticas, não importa muito saber quais são os objetos que se tomam como símbolos primitivos e, para essa finalidade, usaremos os números naturais [nota: isto é, usaremos uma correspondência 1-1 entre os símbolos primitivos e os números naturais]. Assim, uma fórmula é uma sucessão finita de números naturais e a figura de uma demonstração é uma sucessão finita de sucessões finitas de números naturais. Deste modo, os conceitos meta-matemáticos tornam-se conceitos sobre números naturais ou sucessões destes [nota: por outras palavras: o processo descrito acima fornece uma linguagem isomórfica do sistema PM no domínio da aritmética e pode-se perfeitamente efetuar todas os raciocínio meta-matematicamente nesta imagem isomórfica. Isto ocorre no esquema da demonstração que vai se seguir, onde por 'fórmula', 'proposição', 'variável', etc., se entenderá sempre os objetos correspondes da imagem isomórfica.] e por isso é pelos menos parcialmente exprimível no próprio simbolismo do sistema PM. (Gödel 1931, 247-249, grifos nossos)

Tentar fundamentar a matemática matematicamente se ligaria diretamente à suposição de que um problema filosófico poderia ser resolvido com uma prova. Mas a matemática, tanto quanto a própria linguagem, como Wittgenstein sempre ressaltou, não poderia estabelecer seus próprios fundamentos. A matemática não poderia ser metamatemática e, fundamentalmente, a matemática não poderia ser Filosofia. Aqui é importante ressaltar, no entanto, a distinção entre o mero procedimento de gödelização, enquanto um 
mapeamento das sentenças metamatemáticas pela numeração de Gödel, do suposto espelhamento da metamatemática na matemática, que seria uma reformulação, em prosa, das regras do cálculo. Tal suposto espelhamento é que faria a sentença $G$ de Gödel mudar de regra, na medida em que assumiria que o conteúdo referencial da proposição de ordem superior poderia ser lido na proposição aritmética. Apenas o espelhamento permitiria a interpretação da sentença como dizendo algo de si mesma, isto é, apenas o espelhamento permitira a autorreferência, o mero mapeamento seria apenas um procedimento de correlação que não se comprometeria com o colapso entre linguagem e metalinguagem. Dessa forma, o procedimento de correspondência proposto por Gödel estaria bem, na medida em que seria apenas uma técnica de correlacionar números com expressões, mas que nada neste procedimento autorizaria a interpretação em prosa da sentença como dizendo algo de si, o que seria, de acordo com Wittgenstein, uma mudança indevida nas suas regras gramaticais: "'A sentença diz que este número não é alcançável destes números' - Mas você também está certo que a traduziu corretamente em alemão?" (Wittgenstein 2000, item 124 89). De fato, essa distinção aparece claramente no próprio artigo de Gödel, desde que a correspondência é meramente sintática, os números naturais são símbolos como quaisquer outros, mas isto em nada permite a conclusão de que conceitos metamatemáticos se tornem conceitos sobre números e, portanto, expressáveis no próprio sistema do PM, podendo este, assim, falar de si mesmo. Não haveria, de fato, nenhum problema em fazer a correlação, a confusão estaria em, a partir disso, interpretar a sentença como uma proposição falando de si mesma. Aceitar que uma sentença afirme sua própria indemonstrabilidade 
é já aceitar que a matemática possa falar de seus próprios fundamentos. Manter que a sentença que afirma a demonstrabilidade e aquela sobre a qual a demonstrabilidade é afirmada são a mesma subscreve a confusão conceitual que legitima a um sistema matemático provar sua própria consistência.

\section{CONCLUSÃO}

Wittgenstein sempre procurou ressaltar que, em nossos estabelecimentos de ordenações inteligíveis da realidade, usamos sempre a linguagem (verbal e matemática) para formular teorias, e, portanto, não podemos explicar como nossas teorias são capazes de explicar o que consideramos como a realidade sem gerar paradoxos. Poderíamos recorrer a outra teoria, mas isso geraria uma série infinita - quer dizer, podemos elaborar teorias sobre o mundo e essas teorias poderiam ser testadas serem verdadeiras ou falsas, mas não poderíamos elaborar teorias sobre o que nos permite elaborar teorias, porque não poderíamos testar ser verdadeiro ou falso o que nos permite testar o que quer que seja:

Não é a prova de Gödel que me interessa, mas a possibilidade que Gödel nos faz consciente através da sua discussão. A prova de Gödel desenvolve uma dificuldade que deve aparecer em um modo muito mais elementar. E nisso está, me parece, o grande serviço de Gödel à filosofia da matemática, e, ao mesmo tempo, a razão porque não é a sua prova particular que nos interessa. (Wittgenstein 2000, item 163 $37 \mathrm{v})$

Devido ao fato de que um sistema matemático não possa fundamentar a si mesmo, Gödel e Wittgenstein terminam em acordo:

Pode-se perguntar: o que há de profundo nisso? (como: o que é a beleza?) como se nós devêssemos justificar a profundidade apenas atra- 
vés de alguma outra coisa. Isto é profundo. (2000, item $12177 \mathrm{v})$

Os problemas que surgem a partir de uma interpretação incorreta das formas de nossa linguagem têm a marca da profundidade. São inquietações profundas. Suas raízes em nós são tão profundas quanto as formas de nossa linguagem, e sua significância é tão grande quanto a importância que nossa linguagem possui. (IF, 111)

Entretanto, o que extrair disso? Wittgenstein continua: "Os limites do empirismo não são suposições nãogarantidas, ou intuitivamente sabidas corretas: são os modos nos quais fazemos comparações e nos quais agimos" (RFM, VII, 21). E no Da Certeza:

Mas a fundamentação, a justificação da evidência tem um fim - mas o fim não é um facto, certas proposições que se nos apresentam como sendo verdadeiras, isto é, não se trata de uma espécie de ver da nossa parte; é o nosso actuar que está no fundo do nosso jogo de linguagem. (DC, 204)

Como se dar razões não chegasse ao fim alguma vez. Mas o fim não é um pressuposto não fundamentado: é uma via de ação não fundamentada. (DC, 110)

Como vimos, na medida em que aceitamos a demanda de Hilbert - fundamentar matematicamente a matemática -, está posto que devemos nos deparar, mais cedo ou mais tarde, com uma sentença como a de Gödel. Nesse sentido, acreditar que a sentença de Gödel prova o realismo matemático seria a confusão maior. Como já citamos:

Poderia ser dito: Gödel diz que se deve também ser capaz de confiar numa prova matemática quando se deseja concebê-la praticamente como a prova de que o padrão proposicional pode ser construído de acordo com as regras da prova? Ou: uma proposição matemática deve ser capaz de ser concebida como uma proposição de uma geometria que é realmente aplicável a si mesma. E, se se faz isso, isso implica que em certos casos não é possível contar com uma prova. (RFM, VII, 21) 
Com base nessa confusão maior, a prova particular de Gödel é suposta demonstrar a existência de verdades indemonstráveis, ou seja, é suposta legitimar a existência de um ponto de avaliação último, uma abstração definitiva, uma super-realidade análoga à realidade empírica, e isso é o que, para Wittgenstein, engendraria os problemas filosóficos em geral. Quando Wittgenstein comenta Gödel é dessa confusão primordial que ele está falando, por isso só é possível entender seus comentários tendo em vista esse problema, por isso também não é exatamente a prova de Gödel que Wittgenstein comenta. Wittgenstein está fazendo, como sempre, Filosofia, e, portanto, ele tem como objeto questões de ordem conceitual.

Abstract: This paper analyzes the much maligned remarks of Wittgenstein on Gödel's theorem. It is not intended defend these comments, nor argue that Wittgenstein said something that he did not. In fact, it would be impossible ignore what is textual just to provide an interpretation more palatable of the author's position. The purpose of the text is only to clarify the positions really maintained by Wittgenstein on the subject. I hold, as much as possible, that there is some reasonability in Wittgenstein's positions, by taking into count the general scheme of their remarks on mathematics.

Keywords: Wittgenstein; Mathematics; Gödel; Hilbert; Omegainconsistency.

\section{REFERÊNCIAS}

BERNAYS, P. Comments on Ludwig Wittgenstein's remarks on the foundations of Mathematics. Edited by G.H. von Wright, R. Rhes, G.E.M. Anscombe. Oxford: Basil Blackwell, 1956.

DUMMETT, M. The Philosophical Significance of Gödel's Theorem. In: Truth and other enigmas. London: Duckworth, 1978. 
FLOYD, J. Wittgenstein sobre Gödel, Tarski e a Verdade. Revista Portuguesa de Filosofia, tomo LVIII, fasc. 3, p.605632, 2002.

FLOYD, J.; HILARY, P. A note on Wittgenstein's 'notorius paragraph' about the Gödel Theorem. The Journal of Philosoph, v. 97, n. 11, p. 624-633, nov. 2000.

FRANZÉN, T. Gödel's Theorem: An incomplete guide to its use and abuse. Paperback, 2005.

GÖDEL, K. Acerca de proposições formalmente indecidíveis nos Principia Mathematica e sistemas relacionados. Trad. de Manuel Lourenço. In: O Teorema de Gödel e a Hipótese do Contínuo. Lisboa: Calouste, [1931]1979. p. 245-249.

GLOCK, H-J. Dicionário Wittgenstein. Trad. de Helena Martins. Revisão Técnica de Luiz Carlos Pereira. Rio de Janeiro: Jorge Zahar Ed, 1998.

HILBERT. On the Infinite. In: From Frege to Gödel - A source book in Mathematical Logical, 1879-1931. Harvard: Harvard University Press, [1925]1971. p. 367-392.

PERELMAN, C. L'antinomie de M. Gödel. In: Académie Royale de Belgique, Bulletin de la classe des Science, sérei 05, v. 22, p. 730-736, 1936.

READ, R. Gödel's Theorem over-interpreted: There is no such thing as de re self-reference. 2005. Disponível em: http://www.uea.ac.uk/ j339/Godelselfref.htm. Acesso em: 10 jul. 2007.

RUSSELL, B; WHITEHEAD, A. N. Principia Mathematica 
to 56. (PM) Cambridge: Cambridge University Press, 1910.

SAYWARD, C. On some much maligned remarks of Wittgenstein on Gödel. Philosophical Investigations, v. 24, n. 3, p. 262-270, 2001.

SHANKER, S. G. Gödel's Theorem in Focus. Edição de S. G. Shanker. London and New York: Routledge and Kegan Paul, 1989.

SMULLYAN, R. Gödel's incompleteness theorems. In: The Blackwell Guide to Philosophical Logic. Edited by Lou Goble. Oxford: Blackwell, 2001.

TARSKI, A. The concept of truth in formalizad languages. In: Logic, Semantics, Metamathematics. Translations by J. $\mathrm{H}$. Woodger. Oxford: Clarendon Press, 1956. p. 152-278.

WANG, H. Reflexiones sobre Kurt Gödel. Versión española de Pilar Caltilo Criado. Madrid: Alianza Universidad, 1991.

WITTGENSTEIN, L. Tractatus logico-philosophicus. (TLP) Tradução, apresentação, e estudo introdutório: Luiz Henrique Lopes dos Santos. Introdução: Bertrand Russel. São Paulo: Editora da Universidade de São Paulo, 1993.

- Investigações filosóficas . (IF) Trad. de José Carlos Bruni. São Paulo: Nova Cultural, 1989. (Os Pensadores)

- Wittgenstein and the Vienna Circle: conversations recordations by Friedrich Waismann. (WCV) Oxford: Blackwell, 1979.

- Remarks on Foundations of Mathematics. (RFM) Edited by G.H.von Wright, R. Rhees and G. E. M. 
Anscombe. Translated by G. E. M. Anscombe. Oxford: Blackwell, 1967.

. Remarques Philosophiques. (RP) Trad. de Jaques Fauve. Paris : Éditions Gallimard, 1975.

. Philosophical Grammar. (PG) Organizado por R. Rhees. Oxford: Blackwell, 1974.

. Da Certeza. (DC) Trad. de Maria Elisa Costa. Lisboa: Edições 70, 1969.

. Zettel (Fichas) (Z) Lisboa: Edições 70, 1989.

- Wittgenstein's Nachlass. Oxford University: The Bergen Electronic Edition, 2000. 